
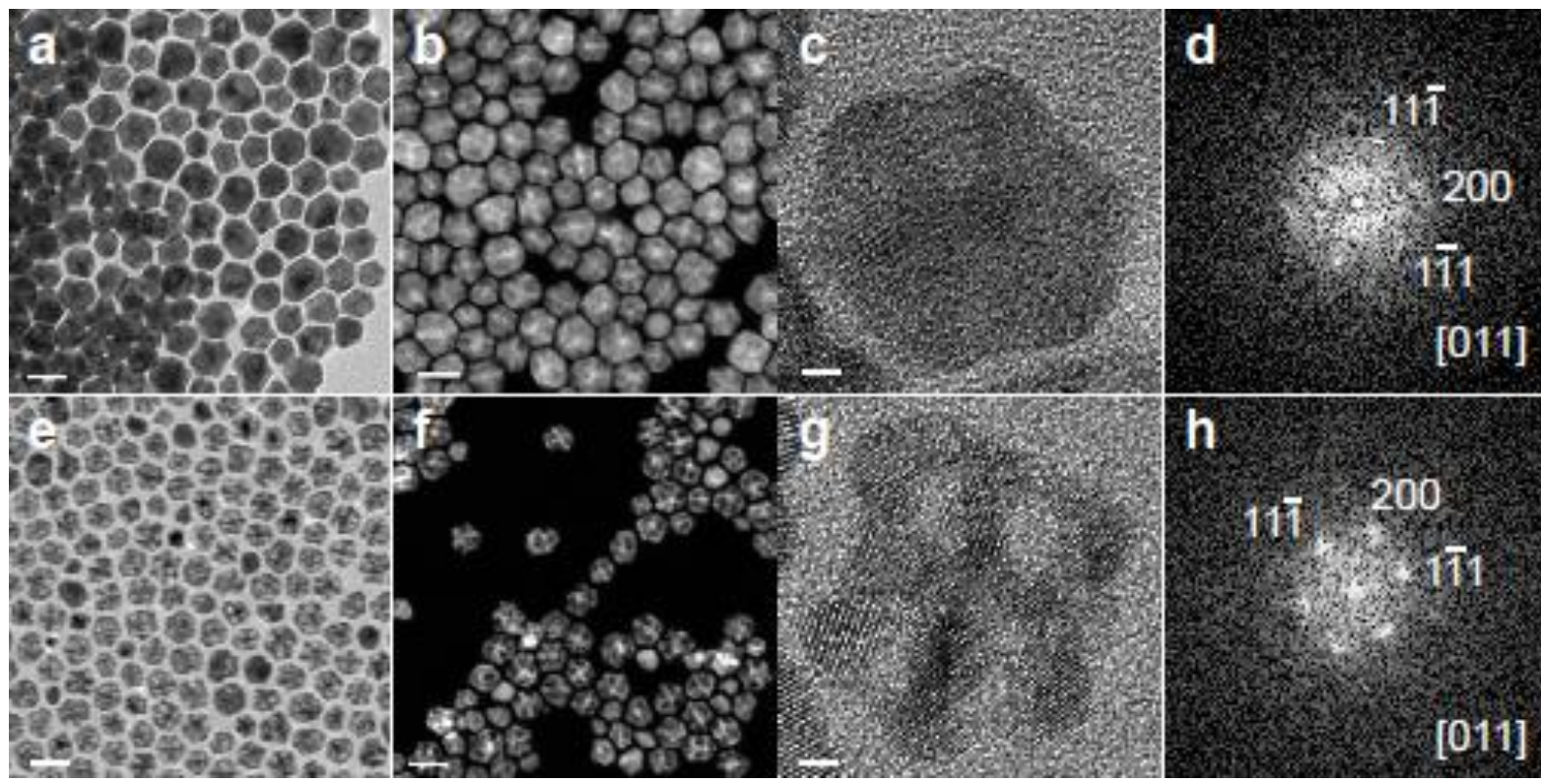

(C) 2015. This manuscript version is made available under the Elsevier user license http:/www.elsevier.com/open-access/userlicense/1.0/ 


\title{
Synthesis of $\mathrm{PtCo}_{3}$ Polyhedral Nanoparticles and Evolution to $\mathrm{Pt}_{3} \mathrm{Co}$ Nanoframes
}

Nigel Becknell ${ }^{\mathrm{a}}$, Cindy Zheng ${ }^{\mathrm{a}}$, Chen Chen ${ }^{\mathrm{a}, \mathrm{b}, 1}$, Yi Yu ${ }^{\mathrm{a}}$, Peidong Yang ${ }^{\mathrm{a}, \mathrm{b}, \mathrm{c}, \text {, }}$

a Department of Chemistry, University of California, Berkeley, Berkeley, California 94720, United States

b Materials Sciences Division, Lawrence Berkeley National Laboratory, 1 Cyclotron Road, Berkeley, California 94720, United States

c Kavli Energy Nanoscience Institute, Berkeley, California 94720, United States

1 Department of Chemistry, Tsinghua University, Beijing 100084, P. R. China

*Email address: p_yang@berkeley.edu

\begin{abstract}
Bimetallic nanoframes have great potential for achieving new levels of catalytic activity in various heterogeneous reactions due to their high surface area dispersion of expensive noble metals on the exterior and interior surfaces of the structure. $\mathrm{PtCo}_{3}$ nanoparticles with polyhedral shapes were synthesized by a hot-injection method. Scanning transmission electron microscopy combined with energy dispersive $\mathrm{x}$-ray spectroscopy (EDS) showed that these nanoparticles demonstrated elemental segregation of platinum to the edges of the polyhedron, forming the basis for a framework nanostructure. The process of preferential oxidative leaching which removed cobalt from the interior of the framework was tracked by EDS and inductively coupled plasma optical emission spectroscopy. This evolution procedure left the platinum-rich edges intact to form a $\mathrm{Pt}_{3} \mathrm{Co}$ nanoframe. This is the first reported synthesis of a platinum-cobalt nanoframe and could have potential applications in catalytic reactions such as oxygen reduction.
\end{abstract}

Keywords: Platinum, cobalt, bimetallic, nanoframe

\section{Introduction}

The importance of nanocrystal synthesis has been emphasized by the applications of nanocrystals in a vast array of fields including catalysis [1, 2], semiconductors [3], electronics [4], plasmonics [5], and magnetism [6, 7]. The nature of nano-sized metallic or semiconducting materials affords them unique and beneficial properties compared to their bulk counterparts. The ability to control the shape and structure of nanoparticles (NPs) can greatly enhance and clarify structure-dependent trends in their properties [8-10]; when two or more metals are incorporated into a single particle, the possibilities for structural control of the particle expand significantly. Bimetallic NPs have been synthesized with various geometries including core-shell [11], random distribution, and heterogeneous distribution [12]. By incorporating two metals into a nanoparticle, the capabilities of the nanoparticle can be diversified due to the synergistic interactions between the two different metals. 
Recently, Yang and co-workers have employed both homogeneous and heterogeneous distributions of elements in bimetallic particles to achieve significant enhancements in catalytic activity for electrochemical carbon dioxide reduction [13] and oxygen reduction [14]. In the latter case, a $\mathrm{PtNi}_{3}$ rhombic dodecahedron was synthesized with heterogeneous distribution of platinum to the edges of the three-dimensional shape. Nickel was then preferentially oxidized from the faces and interior of the polyhedron, leaving a hollow nanoframe (NF) with threedimensional catalytically active surfaces on the interior and exterior of the frame. This work demonstrated a novel method for obtaining a NF by synthesizing a bimetallic NP with heterogeneous distribution of the two elements. This method enables the synthesis of an alloy which can convert from Pt-poor to Pt-rich composition while maintaining the rigid structure of the edges of the shape. Previous work on hollow NF structures involved galvanic replacement of a template nanostructure with a more noble metal [15-18], sequential growth of metal on the edges of a template shape [19], or direct solvothermal synthesis of a hollow NF [20, 21]. More recently, additional work has been done on the synthesis of bimetallic NPs with heterogeneous distribution of a noble metal to the edges of the shape [22-25]. However, to this point, no work has been reported on the synthesis of platinum-cobalt bimetallic NFs.

Platinum-cobalt bimetallic alloys have been extensively studied for their magnetic properties $[26,27]$ and enhanced catalytic activity for the oxygen reduction reaction (ORR) [2835]. The $\mathrm{Pt}_{3} \mathrm{Co}$ phase was synthesized with high monodispersity by reduction of platinum acetylacetonate with concomitant decomposition of cobalt carbonyl [26, 29]. Ordered PtCo NPs have been synthesized by solution-phase methods, which typically result in a disordered face centered cubic structure, and subsequent high temperature annealing to produce the ordered tetragonal PtCo phase [36]. There are very few reports of solution phase synthesis of $\mathrm{PtCo}_{3} \mathrm{NPs}$ [37]. In fact, the platinum-cobalt phase diagram is still in debate, with some suggesting a $\mathrm{PtCo}_{3}$ ordered phase should be possible [38], similar to $\mathrm{PtNi}_{3}$, and others asserting that it is not a stable phase and that the solid solution composition of $75 \%$ cobalt is similarly unfavorable [39]. This is understandable considering that at temperatures below $450^{\circ} \mathrm{C}$, cobalt prefers its epsilon hexagonally close-packed phase [40]. It is well known that platinum strongly prefers cubic closepacking structure, so cobalt-rich platinum alloys are naturally difficult to stabilize and the more stable $\mathrm{PtCo}$ or $\mathrm{Pt}_{3} \mathrm{Co}$ phases are typically preferred. We developed the synthesis of a cobalt-rich Pt-Co polyhedron because the NP must be cobalt-rich in order to make a sufficiently hollow NF by leaching of the Co. Through this synthesis and evolution process, we report the first synthesis of a Pt-rich, platinum-cobalt alloy nanoframe.

\section{Experimental}

\section{1 $\mathrm{PtCo}_{3}$ nanoparticle synthesis}

Chloroplatinic acid hexahydrate $\left(\mathrm{H}_{2} \mathrm{PtCl}_{6} \cdot 6 \mathrm{H}_{2} \mathrm{O}\right)$, cobalt acetate tetrahydrate $\left(\left(\mathrm{CH}_{3} \mathrm{COO}\right)_{2} \mathrm{Co} \cdot 4 \mathrm{H}_{2} \mathrm{O}\right)$, oleylamine (technical grade, $\left.70 \%\right)$ and oleic acid (technical grade, $\left.90 \%\right)$ were purchased from Sigma Aldrich. Chloroplatinic acid $(28.5 \mathrm{mg})$ and cobalt acetate tetrahydrate $(60 \mathrm{mg})$ were dissolved into $285 \mu \mathrm{L}$ ultrapure water and then mixed with $3 \mathrm{~mL}$ oleylamine. This mixture was homogenized by stirring at $60{ }^{\circ} \mathrm{C}$ under nitrogen for 30 minutes. 
Oleylamine $(5 \mathrm{~mL})$ and oleic acid $(2 \mathrm{~mL})$ were added to a $25 \mathrm{~mL}$ three-neck flask and heated at $180{ }^{\circ} \mathrm{C}$ under argon for 45 minutes. Next, the precursor mixture was injected into the three-neck flask and heated under argon flow for 3 minutes. Then, the temperature of the reaction solution was increased to $240^{\circ} \mathrm{C}$. The solution went from dark purple to black. The NP solution was held at $240{ }^{\circ} \mathrm{C}$ for 2 minutes for growth of the particles before being rapidly cooled in a water bath. The particles were washed once with ethanol and a second time with hexanes and ethanol by centrifuging at $12000 \mathrm{rpm}$ for 10 minutes. After washing, the particles could be dispersed in solvents such as hexanes or chloroform.

\subsection{Evolution to $\mathrm{Pt}_{3} \mathrm{Co}$ nanoframes}

The as-synthesized NPs ( $2 \mathrm{mg})$ were dispersed into $2.5 \mathrm{~mL}$ chloroform with $300 \mu \mathrm{L}$ oleylamine added. This solution was then diluted with $10 \mathrm{~mL}$ hexadecane and sonicated for 1 hour. The suspension of NPs was then heated at $130{ }^{\circ} \mathrm{C}$ with occasional sonication required to re-disperse the highly magnetic NPs. After heating for 6 hours, the NPs had fully evolved to hollow NFs.

\subsection{Characterization of Pt-Co nanoparticles and nanoframes}

Nanoparticle and nanoframe samples were imaged by transmission electron microscopy (TEM) using a Hitachi H-7650 TEM and scanning electron microscopy (SEM) using a Zeiss Gemini Ultra-55 Field Emission SEM to determine size and morphology. Energy dispersive spectroscopy (EDS) was also performed with TEM to determine composition of the bimetallic NPs and NFs. High resolution TEM (HRTEM) was performed with an F20 UT Tecnai to confirm crystallinity and structure of the Pt-Co samples. High-angle annular dark-field scanning transmission electron microscopy (HAADF-STEM) and EDS mapping were performed with an FEI TitanX to characterize the elemental distribution in the NPs and NFs.

The crystalline phase of the samples was determined through $\mathrm{X}$-ray diffraction (XRD) with a Bruker D-8 General Area Detector Diffraction System (GADDS) with HI-STAR area CCD detector. The instrument was equipped with a Co-K $\alpha$ source $(\lambda=1.789 \AA)$. The composition of the samples was determined through XRD, EDS, and inductively coupled plasma optical emission spectroscopy (ICP-OES) using a PerkinElmer Optima 7000 DV.

The behavior of the surface of the NPs was analyzed with ambient pressure X-ray photoelectron spectroscopy (AP-XPS) on the Scienta R4000 HiPP endstation at the Lawrence Berkeley National Laboratory Advanced Light Source (ALS) Beamline 9.3.2. Samples were prepared on silicon substrates and mounted on a ceramic button heater sample holder in order to

heat the sample up to $120^{\circ} \mathrm{C}$ during experiments. The atmosphere was controlled at UHV $\left(\sim 10^{-9}\right.$ torr) or 100 mTorr of $\mathrm{H}_{2}$ or $\mathrm{O}_{2}$ by introducing the gases into the chamber through different molecular leak valves. XPS spectra were collected using an incident X-ray energy of $490 \mathrm{eV}$. The binding energy for XPS spectra was calibrated to the Au 4f core level of a Au foil. The XPS spectra were quantitatively analyzed by subtracting a Shirley background.

\section{Results and Discussion}

\section{1 $\mathrm{PtCo}_{3}$ nanoparticle synthesis}


$\mathrm{PtCo}_{3}$ NPs were synthesized by hot-injection of Pt and Co precursors into a mixture of oleylamine and oleic acid. A typical TEM image of the as-synthesized $\mathrm{PtCo}_{3}$ polyhedral NP is shown in Fig. 1a. The size distribution of the $\mathrm{PtCo}_{3} \mathrm{NP}$ was calculated to be $17.1 \pm 2.7 \mathrm{~nm}$. The hexagonal projection, characteristic of a rhombic dodecahedron in the platinum bimetallic, oleylamine-based system, was primarily observed in TEM though there are other polyhedra which form during the synthesis of the $\mathrm{PtCo}_{3}$ NPs. HAADF-STEM imaging was used to screen $\mathrm{PtCo}_{3} \mathrm{NPs}$ for the required heterogeneous elemental distribution because it provides significant contrast difference between atoms of different atomic number [41]. The STEM image of the assynthesized $\mathrm{PtCo}_{3}$ polyhedra in Fig. 1b demonstrates initial proof of segregation of the heavier element, $\mathrm{Pt}$, to the edges of the three-dimensional shape due to the bright contrast which can be seen at the edges.
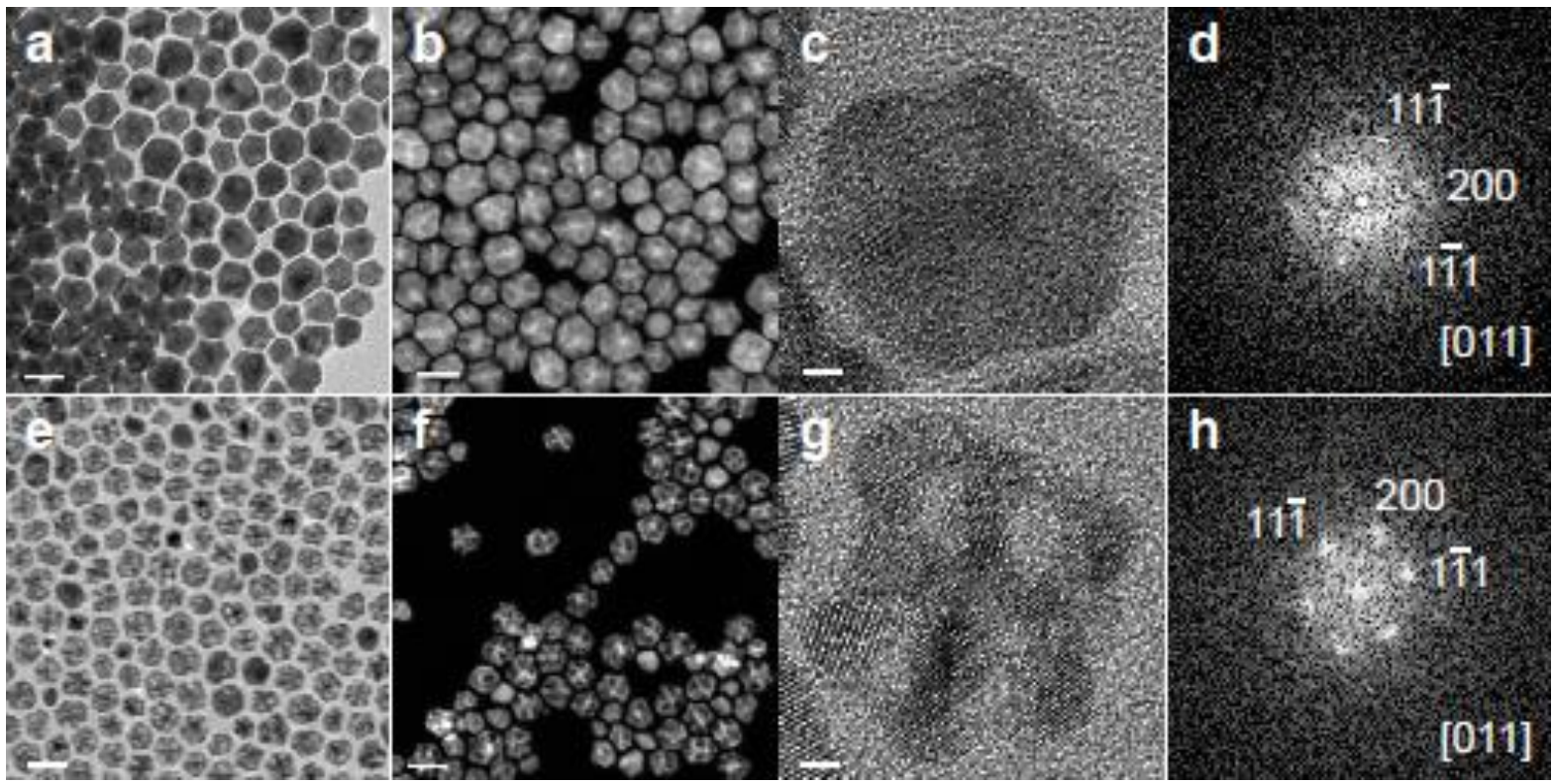

Fig. 1. (a) TEM image of $\mathrm{PtCo}_{3} \mathrm{NP}$. (b) STEM image of $\mathrm{PtCo}_{3} \mathrm{NP}$. (c) HRTEM image of a $\mathrm{PtCo}_{3} \mathrm{NP}$ and (d) corresponding FFT. (e) TEM image of $\mathrm{Pt}_{3} \mathrm{Co}$ NF. (f) STEM image of $\mathrm{Pt}_{3} \mathrm{Co}$ NF. (g) HRTEM image of $\mathrm{Pt}_{3} \mathrm{Co} \mathrm{NF}$ and (h) corresponding FFT. Scale bars in TEM/STEM images are $20 \mathrm{~nm}$. Scale bars in HRTEM images are $2 \mathrm{~nm}$.

A few key aspects of the synthesis enabled it to produce these Co-rich polyhedra. A molar ratio of 4.4:1 Co:Pt (in excess of the 3:1 ratio in the product) was required to accelerate reduction of $\mathrm{Co}^{2+}$ due to its more negative reduction potential compared to that of $\mathrm{Pt}^{4+}$ [42]. In addition, oleylamine acted as a solvent, reducing agent, and surfactant [43, 44], while oleic acid also aided as a surfactant. Oleic acid was introduced into the synthesis to enhance the shape control as it has been shown that oleic acid has a particularly strong affinity for cobalt in many cobalt-based NP syntheses [7, 45-49]. Oleic acid has also been found to improve the effectiveness of oleylamine [49] and their synergistic effect was expected based on the slight temperature increase of their solution upon simple mixing of the two surfactants. Without the presence of the oleic acid, the NPs synthesized were significantly more rounded and the size was 
only $11.9 \pm 1.6 \mathrm{~nm}$ (see supplementary data Fig. S1). This result indicates oleic acid played a key role in stabilizing larger nuclei and sharpening the edges of the polyhedra during the synthesis, a critical point for transformation into the desired hollow NF. These polyhedral shapes were also observed under SEM imaging to confirm their three-dimensional structure (See supplementary data Fig. S2).

\subsection{Evolution from $\mathrm{PtCo}_{3} \mathrm{NP}$ to $\mathrm{Pt}_{3} \mathrm{Co} \mathrm{NF}$}

In order to evolve the $\mathrm{PtCo}_{3} \mathrm{NP}$ to a $\mathrm{Pt}_{3} \mathrm{Co} \mathrm{NF}$, the NPs were dispersed in excess oleylamine and hexadecane and heated at $130^{\circ} \mathrm{C}$ under air atmosphere. While sufficiently stabilized by both oleylamine and oleic acid, the NPs are magnetic and do aggregate over a short period of time after washing. During the initial period of heating, the magnetic NPs continued to settle out, requiring intermediate periods of sonication to re-disperse the particles. However, once a sufficient amount of cobalt was removed, the magnetic moment of the particle could no longer be sustained, so aggregation was not severe and sonication was no longer required. TEM and STEM images of the final evolved $\mathrm{Pt}_{3} \mathrm{Co}$ NFs are shown in Fig. 1e and Fig. 1f. The hollow interior of the polyhedral frame can be seen in bright-field and dark-field images. Compared to the NPs, STEM imaging revealed more uniform intensity, or less contrast, over the area of the $\mathrm{NFs}$, indicating more uniform distribution of $\mathrm{Pt}$ and Co.

\subsection{Structural characterization of $\mathrm{PtCo}_{3} \mathrm{NP}$ and $\mathrm{Pt}_{3} \mathrm{Co} \mathrm{NF}$}

HRTEM (Fig. 1c, d, g, h) imaging and XRD (Fig. 2) indicated that the NPs and NFs had the expected face-centered cubic structure. In the XRD, the peaks corresponded well with $\mathrm{PtCo}_{3}$ for the NP and $\mathrm{Pt}_{3} \mathrm{Co}$ for the NF. These compositions were further supported by EDS and ICP measurements. The NP was determined to be $75 \%$ Co and the NF was $25 \%$ Co by both ICP and EDS. However, the $\mathrm{PtCo}_{3} \mathrm{NP}$ diffraction pattern exhibited asymmetric broadening toward the lower $2 \Theta$ side, indicating the possible formation of other Pt-Co alloys. This is expected according to the known phase stability [39], which favors phase separation to the PtCo composition. Many previous reports illustrate the relatively facile synthesis of $\mathrm{Pt}_{3} \mathrm{Co}$ or PtCo phases [26, 36]. Additionally, a face-centered cubic platinum-cobalt solid solution NP was synthesized with a composition of $\mathrm{Co}_{69} \mathrm{Pt}_{31}$ and while more Pt-rich compositions were demonstrated, increased cobalt content was not [44]. Even impregnation and high-temperature annealing methods do not produce pure phase $\mathrm{PtCo}_{3} \mathrm{NP}$ alloys, but rather a mixture of two or more Pt-Co phases with an average composition of 75\% Co and 25\% Pt [33, 50-52]. For example, Strasser et al reported via Rietveld analysis that their $\mathrm{PtCo}_{3}$ sample actually consisted of $74.8 \pm 2.2 \mathrm{wt} \% \mathrm{Pt}_{47} \mathrm{Co}_{53}$ and $25.2 \pm 2.1 \mathrm{wt} \% \mathrm{Pt}_{5} \mathrm{Co}_{95}$ [50], consistent with the Pt-Co phase diagram reported by Okamoto [39]. We also observed some Pt-rich NP impurities. Fig. 1f shows that some solid spherical particles remained in the NF sample and these particles exhibit little contrast in the HAADF image, indicating that they were platinum-rich impurity particles in the initial $\mathrm{PtCo}_{3} \mathrm{NP}$ synthesis. The diffraction pattern for the NF sample consists of symmetric peaks with significantly less broadening than that observed in the NP XRD pattern. Therefore, after evolution, the sample consists of homogeneous $\mathrm{Pt}_{3} \mathrm{Co}$ NFs with some spherical impurities which were likely synthesized as $\mathrm{Pt}_{3} \mathrm{Co}$ initially. 


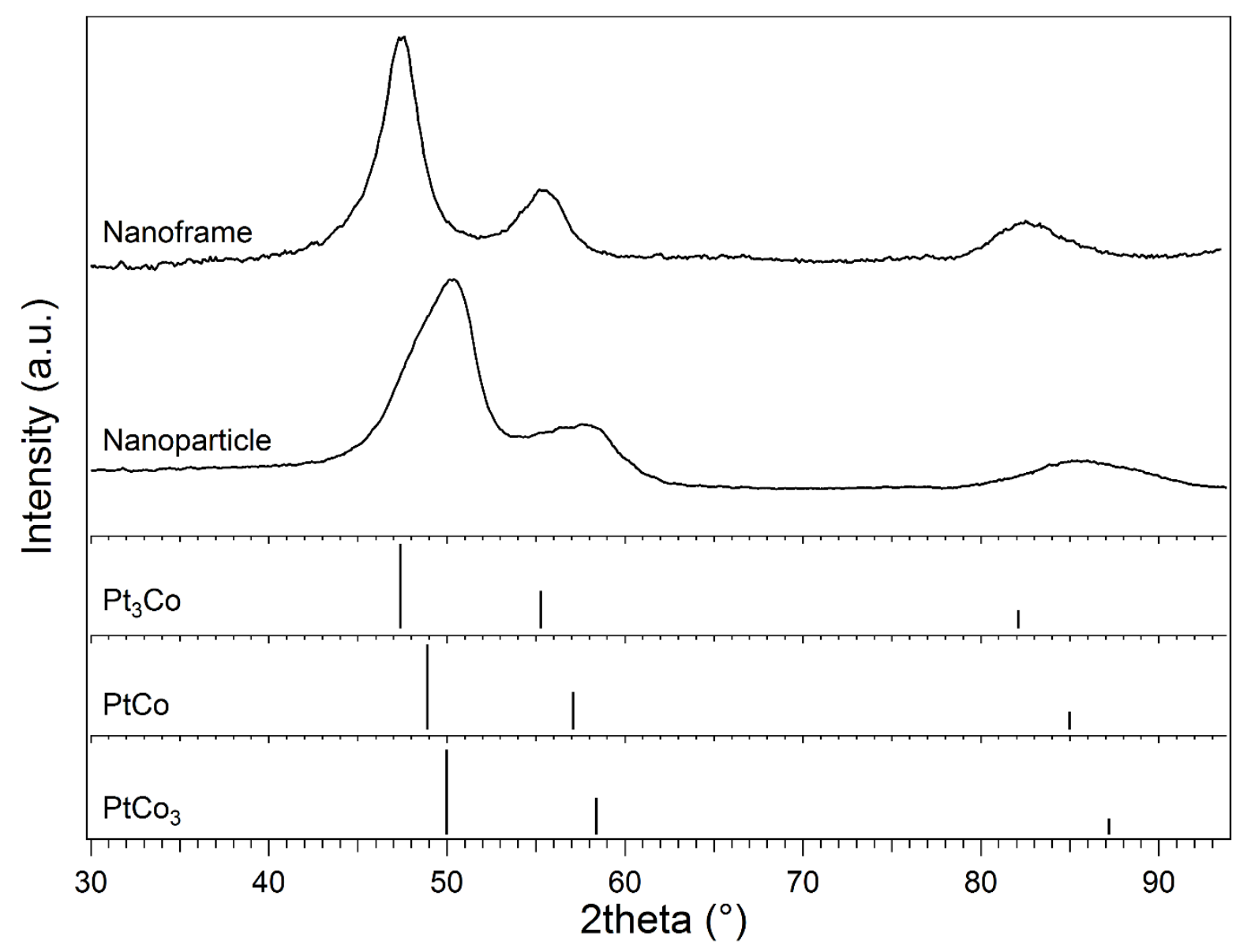

Fig. 2. XRD patterns of $\mathrm{PtCo}_{3} \mathrm{NP}$ and $\mathrm{Pt}_{3} \mathrm{Co} \mathrm{NF}$. Diffraction patterns for $\mathrm{Pt}_{3} \mathrm{Co}$ (JCPDS 01-0729178), PtCo (03-065-8970), and $\mathrm{PtCo}_{3}$ (01-071-7411) are shown for comparison.

\subsection{Compositional characterization of $\mathrm{PtCo}_{3} \mathrm{NP}$ and $\mathrm{Pt}_{3} \mathrm{Co} \mathrm{NF}$}

HAADF-STEM imaging and corresponding EDS mapping in Fig. 3a-d further prove that the $\mathrm{PtCo}_{3}$ polyhedral NPs were synthesized with platinum enrichment on the edges. In the $\mathrm{PtCo}_{3}$ NP, the edges exhibit brighter contrast (Fig. 3a) due to the enrichment of the heavier element, platinum. This is corroborated by elemental mapping which shows a cobalt-rich core (Fig. 3c) and a platinum framework (Fig. 3d) which has formed in the as-synthesized NP. Evolution of this NP yields a NF in which the HAADF imaging contrast is more uniform (Fig. 3e) and the elemental mapping demonstrates homogeneous distribution of the elements (Fig. 3f-h). The composition of the NPs could also be tracked during the evolution process via quantitative EDS (Fig. 4). The measured EDS composition matched well with the XRD and ICP-OES results in that the NP began with a composition of $75 \% \mathrm{Co}$, but leaching of the cobalt from the particle during solution-phase oxidation led to a NF with $25 \%$ Co composition. 

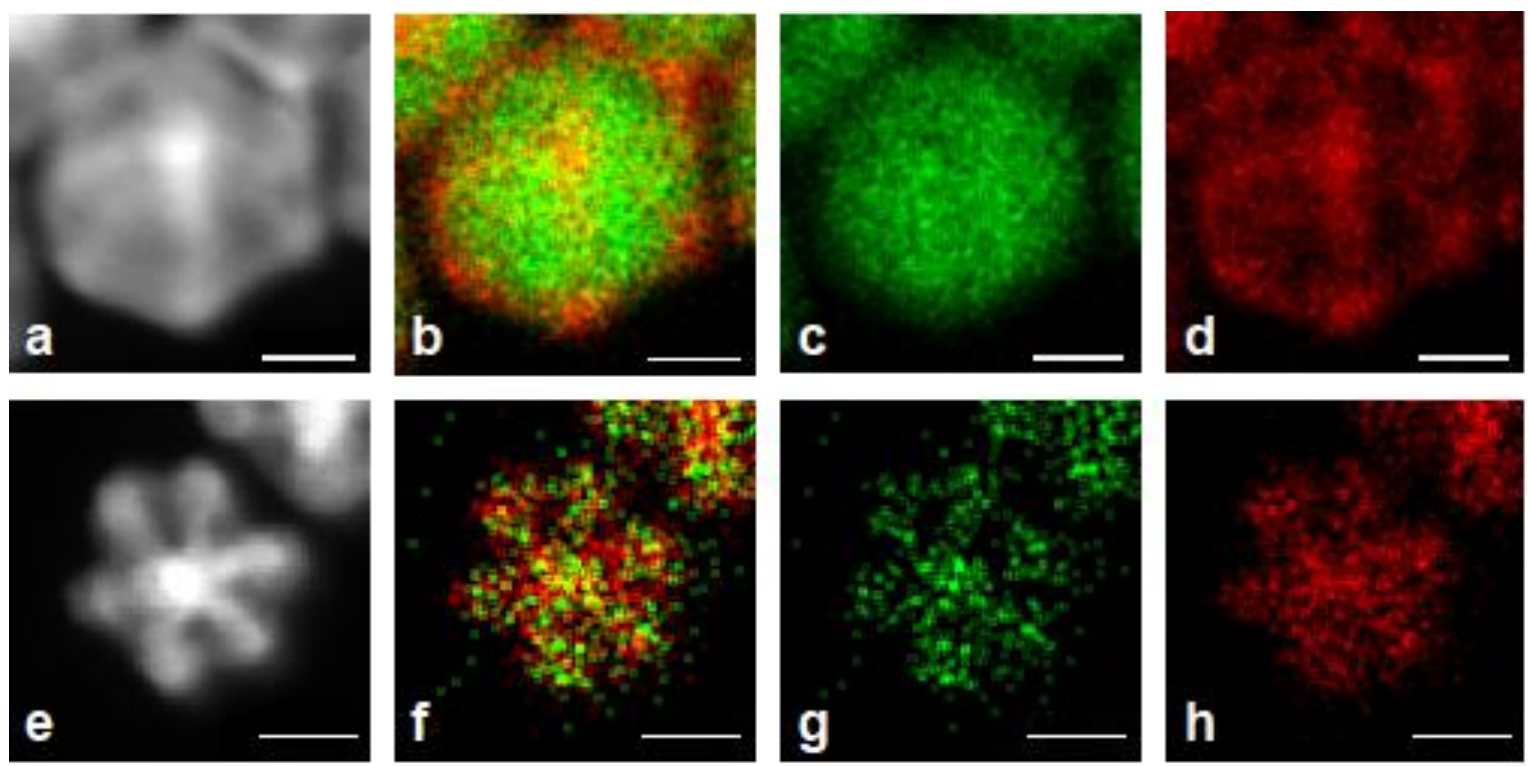

Fig. 3. (a) HAADF-STEM image of $\mathrm{PtCo}_{3} \mathrm{NP}$ and (b) corresponding EDS elemental mapping with separate maps shown for (c) Co and (d) Pt. (e) HAADF-STEM image of $\mathrm{Pt}_{3} \mathrm{Co}$ NF and (f) corresponding EDS elemental mapping with separate maps shown for (g) Co and (h) Pt. All scale bars are $6 \mathrm{~nm}$.

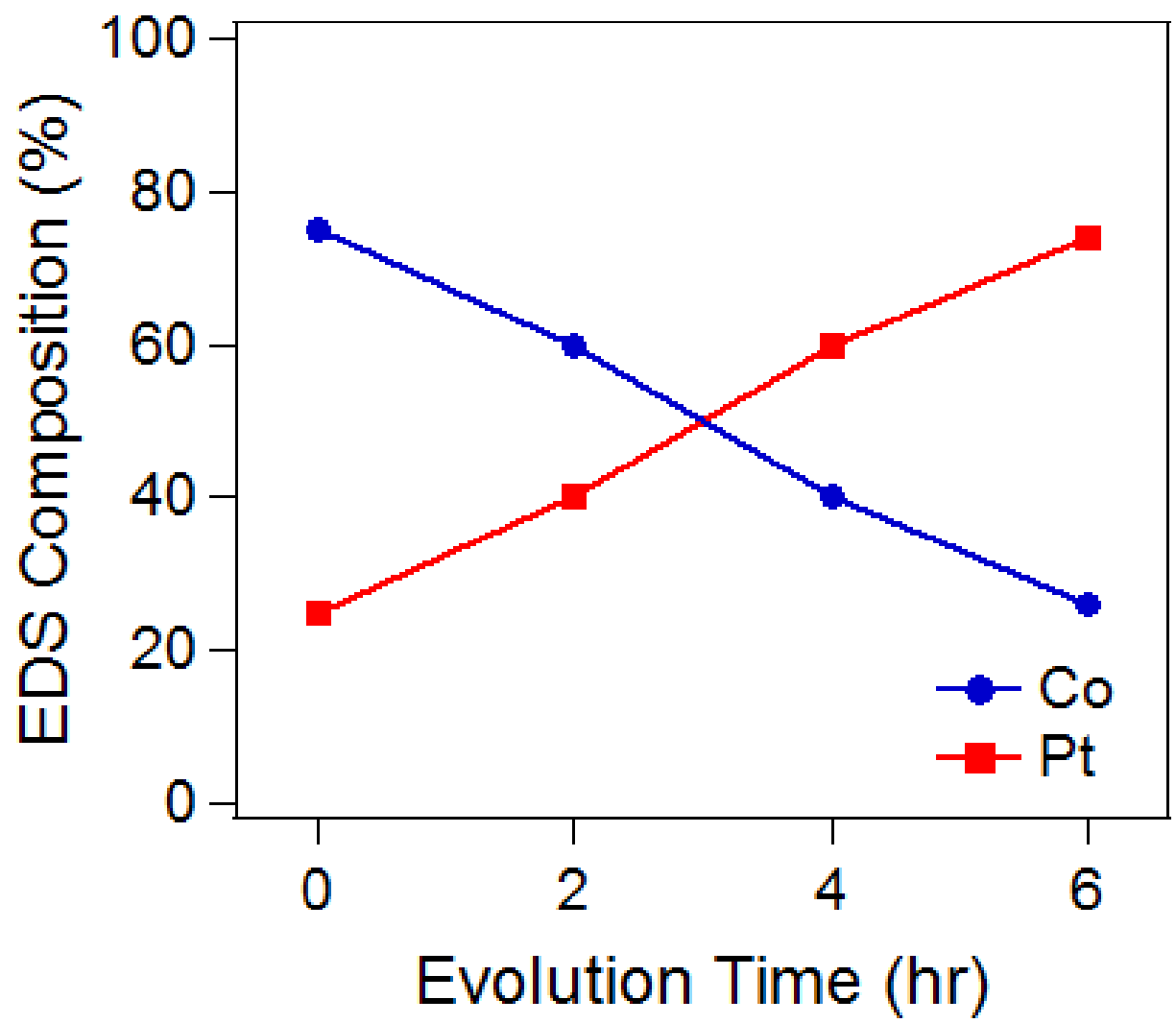

Fig. 4. Compositional evolution from $\mathrm{PtCo}_{3} \mathrm{NP}$ to $\mathrm{Pt}_{3} \mathrm{Co} \mathrm{NF}$ at $130{ }^{\circ} \mathrm{C}$ as tracked by EDS. 


\subsection{AP-XPS of $\mathrm{PtCo}_{3} \mathrm{NP}$ in different atmospheres}

Further proof of the favorable oxidative leaching process was obtained through AP-XPS experiments at the ALS Beamline 9.3.2. Although XPS is a difficult method for achieving accurate quantification, the general trends of surface composition can be elucidated. The incident photon energy was tuned to $490 \mathrm{eV}$, corresponding to an inelastic mean free path of approximately $0.9 \mathrm{~nm}$ [53]. The changes in surface composition of the $\mathrm{PtCo}_{3} \mathrm{NP}$ due to different environments in the XPS chamber are shown in Fig. 5. A sample background-subtracted XPS spectrum is shown in Figure S3. Initially, it was found that the surface of the $\mathrm{PtCo}_{3} \mathrm{NPs}$ may have been slightly enriched in Pt. Annealing of the NP in $100 \mathrm{mTorr}_{2}$ at $120^{\circ} \mathrm{C}$ only furthered this enrichment of $\mathrm{Pt}$ at the surface. Subsequent annealing in $100 \mathrm{mTorr} \mathrm{O}_{2}$ at $120^{\circ} \mathrm{C}$ produced a drastic increase in the concentration of $\mathrm{Co}$ at the surface of the NP. A similar increase in surface $\mathrm{Ni}$ concentration under $\mathrm{O}_{2}$ was observed in the corresponding $\mathrm{PtNi}_{3}$ nanoparticle [14]. A final annealing step in $\mathrm{H}_{2}$ served to once again induce surface segregation of $\mathrm{Pt}$ in the $\mathrm{PtCo}_{3} \mathrm{NP}$. These results demonstrate the ability of cobalt to surface segregate and be oxidized under an air atmosphere at moderately high temperature in these NPs. Therefore, the removal of cobalt from the $\mathrm{PtCo}_{3} \mathrm{NP}$ and evolution to the hollow $\mathrm{Pt}_{3} \mathrm{Co} \mathrm{NF}$ was able to proceed quite easily and over a short period of time.

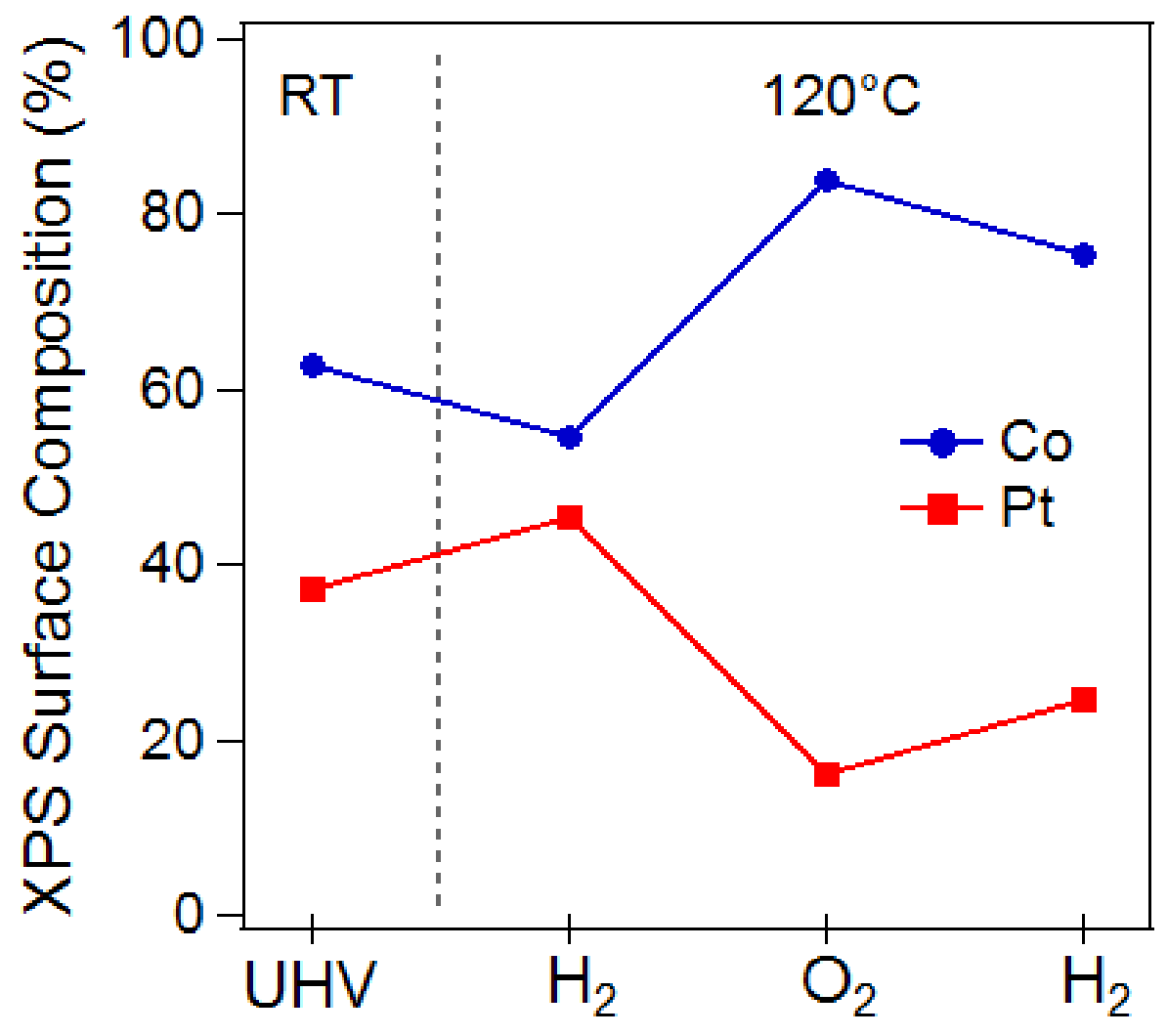

Fig. 5. AP-XPS quantitative analysis of surface composition. Initial spectrum was taken at approximately $10^{-9}$ Torr (UHV) at room temperature (RT). Subsequent annealing was performed in $100 \mathrm{mTorr}$ of $\mathrm{H}_{2}$ or $\mathrm{O}_{2}$ while the sample was heated at $120^{\circ} \mathrm{C}$. 


\section{Conclusion}

$\mathrm{PtCo}_{3}$ NPs with segregation of platinum to the edges of their polyhedral shape were synthesized by co-reduction of platinum and cobalt precursor salts. Shape control was achieved by utilizing a dual surfactant system of oleylamine and oleic acid. Due to the heterogeneous distribution of the elements in the polyhedron, cobalt was able to easily oxidize as shown in APXPS experiments. This allowed for leaching of cobalt from the NP and evolution to a hollow NF by solution-phase oxidation. The hollow $\mathrm{Pt}_{3} \mathrm{Co} \mathrm{NF}$ is the first platinum-cobalt alloy nanoframe and could have important applications in areas such as catalysis. Specifically, the alloy composition and framework structure could potentially provide excellent oxygen reduction reaction activity which is currently under investigation.

\section{Acknowledgements}

This research was supported by the Office of Science, Office of Basic Energy Sciences, of the U.S. Department of Energy under Contract No. DE-AC02-05CH11231(Surface). We would like to thank Professor Paul Alivisatos for access to the Bruker D-8 XRD, the Molecular Foundry at Lawrence Berkeley National Laboratory for access to the Zeiss SEM and electron microscopes at the National Center for Electron Microscopy, Dohyung Kim for assistance with SEM imaging, Ethan Crumlin for assistance at ALS Beamline 9.3.2, and Elena Kreimer of the Microanalytical Facility in the College of Chemistry, UC Berkeley for access to ICP. The Advanced Light Source is supported by the Director, Office of Science, Office of Basic Energy Sciences, of the U.S. Department of Energy under Contract No. DE-AC02-05CH11231. Work at the Molecular Foundry was supported by the Office of Science, Office of Basic Energy Sciences, of the U.S. Department of Energy under Contract No. DE-AC02-05CH11231.

\section{Appendix A. Supplementary data}

Supplementary data for this article can be found online.

\section{References}

[1] G.A. Somorjai, J.Y. Park, Colloid science of metal nanoparticle catalysts in 2D and 3D structures. Challenges of nucleation, growth, composition, particle shape, size control and their influence on activity and selectivity, Topics in Catalysis, 49 (2008) 126-135.

[2] A.T. Bell, The impact of nanoscience on heterogeneous catalysis, Science, 299 (2003) 1688-1691.

[3] Y. Yin, A.P. Alivisatos, Colloidal nanocrystal synthesis and the organic-inorganic interface, Nature, 437 (2005) 664-670.

[4] D.V. Talapin, J.-S. Lee, M.V. Kovalenko, E.V. Shevchenko, Prospects of colloidal nanocrystals for electronic and optoelectronic applications, Chem. Rev., 110 (2009) 389-458.

[5] A. Tao, P. Sinsermsuksakul, P. Yang, Tunable plasmonic lattices of silver nanocrystals, Nat. Nanotechnol., 2 (2007) 435-440.

[6] S.H. Sun, C.B. Murray, D. Weller, L. Folks, A. Moser, Monodisperse FePt nanoparticles and ferromagnetic FePt nanocrystal superlattices, Science, 287 (2000) 1989-1992. 
[7] C.B. Murray, S.H. Sun, H. Doyle, T. Betley, Monodisperse 3d transition-metal (Co, Ni, Fe) nanoparticles and their assembly into nanoparticle superlattices, MRS Bull., 26 (2001) 985-991.

[8] K.M. Bratlie, H. Lee, K. Komvopoulos, P. Yang, G.A. Somorjai, Platinum nanoparticle shape effects on benzene hydrogenation selectivity, Nano Lett., 7 (2007) 3097-3101.

[9] H. Song, F. Kim, S. Connor, G.A. Somorjai, P. Yang, Pt nanocrystals: Shape control and LangmuirBlodgett monolayer formation, J. Phys. Chem. B, 109 (2005) 188-193.

[10] Y. Yin, R.M. Rioux, C.K. Erdonmez, S. Hughes, G.A. Somorjai, A.P. Alivisatos, Formation of hollow nanocrystals through the nanoscale Kirkendall effect, Science, 304 (2004) 711-714.

[11] S.E. Habas, H. Lee, V. Radmilovic, G.A. Somorjai, P. Yang, Shaping binary metal nanocrystals through epitaxial seeded growth, Nat. Mater., 6 (2007) 692-697.

[12] N. Toshima, T. Yonezawa, Bimetallic nanoparticles - novel materials for chemical and physical applications, New J. Chem., 22 (1998) 1179-1201.

[13] D. Kim, J. Resasco, Y. Yu, A.M. Asiri, P. Yang, Synergistic geometric and electronic effects for electrochemical reduction of carbon dioxide using gold-copper bimetallic nanoparticles, Nat. Commun., 5 (2014).

[14] C. Chen, Y. Kang, Z. Huo, Z. Zhu, W. Huang, H.L. Xin, J.D. Snyder, D. Li, J.A. Herron, M. Mavrikakis, M. Chi, K.L. More, Y. Li, N.M. Marković, G.A. Somorjai, P. Yang, V.R. Stamenkovic, Highly crystalline multimetallic nanoframes with three-dimensional electrocatalytic surfaces, Science, 343 (2014) 1339-1343.

[15] G.S. Metraux, Y.C. Cao, R.C. Jin, C.A. Mirkin, Triangular nanoframes made of gold and silver, Nano Lett., 3 (2003) 519-522.

[16] X.M. Lu, L. Au, J. McLellan, Z.Y. Li, M. Marquez, Y.N. Xia, Fabrication of cubic nanocages and nanoframes by dealloying $\mathrm{Au} / \mathrm{Ag}$ alloy nanoboxes with an aqueous etchant based on $\mathrm{Fe}\left(\mathrm{NO}_{3}\right)_{3}$ or $\mathrm{NH}_{4} \mathrm{OH}$, Nano Lett., 7 (2007) 1764-1769.

[17] X. Hong, D.S. Wang, S.F. Cai, H.P. Rong, Y.D. Li, Single-Crystalline Octahedral Au-Ag Nanoframes, J. Am. Chem. Soc., 134 (2012) 18165-18168.

[18] M.A. Mahmoud, M.A. El-Sayed, Gold Nanoframes: Very High Surface Plasmon Fields and Excellent Near-Infrared Sensors, J. Am. Chem. Soc., 132 (2010) 12704-12710.

[19] S.F. Xie, N. Lu, Z.X. Xie, J.G. Wang, M.J. Kim, Y.N. Xia, Synthesis of Pd-Rh Core-Frame Concave Nanocubes and Their Conversion to Rh Cubic Nanoframes by Selective Etching of the Pd Cores, Angew. Chem.-Int. Ed., 51 (2012) 10266-10270.

[20] B.Y. Xia, H.B. Wu, X. Wang, X.W. Lou, One-Pot Synthesis of Cubic $\mathrm{PtCu}_{3}$ Nanocages with Enhanced Electrocatalytic Activity for the Methanol Oxidation Reaction, J. Am. Chem. Soc., 134 (2012) 13934-13937.

[21] F. Nosheen, Z.C. Zhang, J. Zhuang, X. Wang, One-pot fabrication of single-crystalline octahedral Pt$\mathrm{Cu}$ nanoframes and their enhanced electrocatalytic activity, Nanoscale, 5 (2013) 3660-3663.

[22] L. Han, H. Liu, P. Cui, Z. Peng, S. Zhang, J. Yang, Alloy $\mathrm{Cu}_{3} \mathrm{Pt}$ nanoframes through the structure evolution in Cu-Pt nanoparticles with a core-shell construction, Sci. Rep., 4 (2014).

[23] Y. Wu, D. Wang, G. Zhou, R. Yu, C. Chen, Y. Li, Sophisticated Construction of Au Islands on PtNi: An Ideal Trimetallic Nanoframe Catalyst, J. Am. Chem. Soc., 136 (2014) 11594-11597.

[24] A. Oh, H. Baik, D.S. Choi, J.Y. Cheon, B. Kim, H. Kim, S.J. Kwon, S.H. Joo, Y. Jung, K. Lee, Skeletal Octahedral Nanoframe with Cartesian Coordinates via Geometrically Precise Nanoscale Phase Segregation in a Pt@ Ni Core-Shell Nanocrystal, ACS Nano, 9 (2015) 2856-2867.

[25] Y. Wang, Y. Chen, C. Nan, L. Li, D. Wang, Q. Peng, Y. Li, Phase-transfer interface promoted corrosion from $\mathrm{PtNi}_{10}$ nanoctahedra to $\mathrm{Pt}_{4} \mathrm{Ni}$ nanoframes, Nano Res., (2015) 1-16.

[26] E.V. Shevchenko, D.V. Talapin, A.L. Rogach, A. Kornowski, M. Haase, H. Weller, Colloidal synthesis and self-assembly of $\mathrm{CoPt}_{3}$ nanocrystals, J. Am. Chem. Soc., 124 (2002) 11480-11485.

[27] E.V. Shevchenko, D.V. Talapin, H. Schnablegger, A. Kornowski, Ö. Festin, P. Svedlindh, M. Haase, H. Weller, Study of nucleation and growth in the organometallic synthesis of magnetic alloy nanocrystals: the role of nucleation rate in size control of $\mathrm{CoPt}_{3}$ nanocrystals, J. Am. Chem. Soc., 125 (2003) 90909101. 
[28] Y. Xu, A.V. Ruban, M. Mavrikakis, Adsorption and dissociation of O-2 on Pt-Co and Pt-Fe alloys, J. Am. Chem. Soc., 126 (2004) 4717-4725.

[29] C. Wang, D. van der Vilet, K.C. Chang, H.D. You, D. Strmcnik, J.A. Schlueter, N.M. Markovic, V.R. Stamenkovic, Monodisperse $\mathrm{Pt}_{3}$ Co Nanoparticles as a Catalyst for the Oxygen Reduction Reaction: Size-Dependent Activity, J. Phys. Chem. C, 113 (2009) 19365-19368.

[30] C. Wang, G.F. Wang, D. van der Vliet, K.C. Chang, N.M. Markovic, V.R. Stamenkovic, Monodisperse $\mathrm{Pt}_{3} \mathrm{Co}$ nanoparticles as electrocatalyst: the effects of particle size and pretreatment on electrocatalytic reduction of oxygen, Phys. Chem. Chem. Phys., 12 (2010) 6933-6939.

[31] C. Wang, M.F. Chi, D.G. Li, D. van der Vliet, G.F. Wang, Q.Y. Lin, J.F. Mitchell, K.L. More, N.M. Markovic, V.R. Stamenkovic, Synthesis of Homogeneous Pt-Bimetallic Nanoparticles as Highly Efficient Electrocatalysts, ACS Catalysis, 1 (2011) 1355-1359.

[32] C. Wang, N.M. Markovic, V.R. Stamenkovic, Advanced Platinum Alloy Electrocatalysts for the Oxygen Reduction Reaction, ACS Catalysis, 2 (2012) 891-898.

[33] H. Schulenburg, E. Muller, G. Khelashvili, T. Roser, H. Bonnemann, A. Wokaun, G.G. Scherer, Heat-Treated $\mathrm{PtCo}_{3}$ Nanoparticles as Oxygen Reduction Catalysts, J. Phys. Chem. C, 113 (2009) 40694077.

[34] D.L. Wang, H.L.L. Xin, R. Hovden, H.S. Wang, Y.C. Yu, D.A. Muller, F.J. DiSalvo, H.D. Abruna, Structurally ordered intermetallic platinum-cobalt core-shell nanoparticles with enhanced activity and stability as oxygen reduction electrocatalysts, Nat. Mater., 12 (2013) 81-87.

[35] J.B. Wu, A. Gross, H. Yang, Shape and Composition-Controlled Platinum Alloy Nanocrystals Using Carbon Monoxide as Reducing Agent, Nano Lett., 11 (2011) 798-802.

[36] V. Tzitzios, D. Niarchos, G. Margariti, J. Fidler, D. Petridis, Synthesis of CoPt nanoparticles by a modified polyol method: characterization and magnetic properties, Nanotechnol., 16 (2005) 287.

[37] T.O. Ely, C. Pan, C. Amiens, B. Chaudret, F. Dassenoy, P. Lecante, M.-J. Casanove, A. Mosset, M. Respaud, J.-M. Broto, Nanoscale Bimetallic Co x Pt1-x Particles Dispersed in Poly (vinylpyrrolidone): Synthesis from Organometallic Precursors and Characterization, J. Phys. Chem. B, 104 (2000) 695-702. [38] J. Sanchez, J. Moran-Lopez, C. Leroux, M. Cadeville, Magnetic properties and chemical ordering in Co-Pt, J. of Phys.: Condens. Matter, 1 (1989) 491.

[39] H. Okamoto, Co-Pt (cobalt-platinum), J. Phase Equilib., 22 (2001) 591-591.

[40] B. Lee, R. Alsenz, A. Ignatiev, M. Van Hove, Surface structures of the two allotropic phases of cobalt, Phys. Rev. B, 17 (1978) 1510.

[41] S. Pennycook, Z-contrast STEM for materials science, Ultramicroscopy, 30 (1989) 58-69.

[42] P. Vanysek, Electrochemical series, Handb. Chem. Phys., 88 (1998).

[43] S. Mourdikoudis, L.M. Liz-Marzan, Oleylamine in Nanoparticle Synthesis, Chem. Mater., 25 (2013) 1465-1476.

[44] Y. Yu, W. Yang, X. Sun, W. Zhu, X.-Z. Li, D. Sellmyer, S. Sun, Monodisperse MPt (M= Fe, Co, Ni, $\mathrm{Cu}, \mathrm{Zn})$ Nanoparticles Prepared from a Facile Oleylamine Reduction of Metal Salts, Nano Lett., 14 (2014) 2778-2782.

[45] S. Sun, C. Murray, Synthesis of monodisperse cobalt nanocrystals and their assembly into magnetic superlattices, J. Appl. Phys., 85 (1999) 4325-4330.

[46] V.F. Puntes, K.M. Krishnan, A.P. Alivisatos, Colloidal nanocrystal shape and size control: The case of cobalt, Science, 291 (2001) 2115-2117.

[47] J. Zhang, J.Y. Fang, A General Strategy for Preparation of Pt 3d-Transition Metal (Co, Fe, Ni)

Nanocubes, J. Am. Chem. Soc., 131 (2009) 18543-18547.

[48] J.L. Zhao, M. Spasova, Z.A. Li, M. Zharnikov, Ferromagnetic Cobalt Nanoparticles and Their Immobilization on Monomolecular Films and Chemical Templates, Adv. Funct. Mater., 21 (2011) 47244735.

[49] N.S. Porter, H. Wu, Z.W. Quan, J.Y. Fang, Shape-Control and Electrocatalytic ActivityEnhancement of Pt-Based Bimetallic Nanocrystals, Acc. Chem. Res., 46 (2013) 1867-1877.

[50] M. Oezaslan, F. Hasché, P. Strasser, Oxygen electroreduction on $\mathrm{PtCo}_{3}, \mathrm{PtCo}$ and $\mathrm{Pt}_{3} \mathrm{Co}$ alloy nanoparticles for alkaline and acidic PEM fuel cells, J. Electrochem. Soc., 159 (2012) B394-B405. 
[51] F. Hasché, M. Oezaslan, P. Strasser, Activity, stability, and degradation mechanisms of dealloyed $\mathrm{PtCu}_{3}$ and $\mathrm{PtCo}_{3}$ nanoparticle fuel cell catalysts, ChemCatChem, 3 (2011) 1805-1813.

[52] M. Oezaslan, P. Strasser, Activity of dealloyed $\mathrm{PtCo}_{3}$ and $\mathrm{PtCu}_{3}$ nanoparticle electrocatalyst for oxygen reduction reaction in polymer electrolyte membrane fuel cell, J. Power Sources, 196 (2011) 52405249.

[53] C. Powell, A. Jablonski, NIST Electron Inelastic-Mean-Free-Path Database, Version 1.2, SRD 71; National Institute of Standards and Technology: Gaithersburg, MD, 2010. 